\title{
Article \\ Optimizing a Reverse Supply Chain Network for Electronic Waste under Risk and Uncertain Factors
}

\author{
Linh Thi Truc Doan ${ }^{1,2, *}$, Yousef Amer ${ }^{1}$, Sang-Heon Lee ${ }^{1} \mathbb{1}$, Phan Nguyen Ky Phuc ${ }^{3}$ and Tham Thi Tran ${ }^{2, *}$ \\ 1 UniSA STEM, University of South Australia, 101 Currie St, Adelaide, SA 5001, Australia; \\ Yousef.Amer@unisa.edu.au (Y.A.); Sang-Heon.Lee@unisa.edu.au (S.-H.L.) \\ 2 Department of Industrial Management, Can Tho University, Can Tho 900000, Vietnam \\ 3 Department of Industrial System Engineering, Ho Chi Minh International University, \\ Ho Chi Minh 700000, Vietnam; pnkphuc@hcmiu.edu.vn \\ * Correspondence: linh.doan@unisa.edu.au (L.T.T.D.); tttham@ctu.edu.vn (T.T.T.)
}

Citation: Doan, L.T.T.; Amer, Y.; Lee, S.-H.; Phuc, P.N.K.; Tran, T.T. Optimizing a Reverse Supply Chain Network for Electronic Waste under Risk and Uncertain Factors. Appl. Sci. 2021, 11, 1946. https://doi.org/ 10.3390/app11041946

Academic Editor: Elza Bontempi

Received: 28 January 2021

Accepted: 18 February 2021

Published: 23 February 2021

Publisher's Note: MDPI stays neutral with regard to jurisdictional claims in published maps and institutional affiliations.

Copyright: (C) 2021 by the authors. Licensee MDPI, Basel, Switzerland. This article is an open access article distributed under the terms and conditions of the Creative Commons Attribution (CC BY) license (https:// creativecommons.org/licenses/by/ $4.0 /)$.

\begin{abstract}
Minimizing the impact of electronic waste (e-waste) on the environment through designing an effective reverse supply chain (RSC) is attracting the attention of both industry and academia. To obtain this goal, this study strives to develop an e-waste RSC model where the input parameters are fuzzy and risk factors are considered. The problem is then solved through crisp transformation and decision-makers are given the right to choose solutions based on their satisfaction. The result shows that the proposed model provides a practical and satisfactory solution to compromise between the level of satisfaction of constraints and the objective value. This solution includes strategic and operational decisions such as the optimal locations of facilities (i.e., disassembly, repairing, recycling facilities) and the flow quantities in the RSC.
\end{abstract}

Keywords: electronic waste; fuzzy mixed integer linear programming; e-waste reverse supply chain; risk and uncertainty

\section{Introduction}

The latest technological advances have considerably shortened the lifetime of electronic products. Currently, obsolete or old electronics are rapidly being replaced by new models with more advanced functions and attractive designs [1]. This has led to electronic waste (e-waste) being one of the world's fastest-growing wastes and it is estimated to increase to 52.2 million tonnes (mt) of e-waste in 2021 [2]. Current statistics show that China is the world's top e-waste producer, having generated 10.1 million tonness of e-waste in 2019. These numbers for Africa, America, Asia, and Europe are $2.9 \mathrm{mt}, 13.1 \mathrm{mt}, 24.9 \mathrm{mt}$, and $12.9 \mathrm{mt}$, respectively. Values of raw materials which can be extracted from e-waste are 3.2 billion, 14.2 billion, 26.4 billion, and 12.9 billion regarding Africa, America, Asia, and Europe, respectively. The data have shown that e-waste is a valuable resource and has a crucial impact on the economy [3]. The mismanagement of e-waste can lead to serious effects for the environment and humans [4,5]. For instance, a large amount of e-waste in Guiyu, China, which is normally processed with manual methods and improper techniques, resulted in significant impacts on soil, water, and human health [6]. However, e-waste also comprises approximately 60 different types of metals including some valuable metals such as gold, copper, aluminum, silver, steel, and iron [7]. To diminish the significant impact of e-waste and recover valuable raw materials, a reverse supply chain (RSC) operation is considered as an effective approach [8,9]. RSC is a set of different activities which aims to reuse or recycle a returned/used product from end-users or dispose of it suitably [10]. Competitive advantages, customer loyalty, environmental regulations compliance, and cost reduction can be achieved through RSC operation [11-15].

RSC has been investigated by many scholars [16-28]. However, most research considers parameters in RSC that are deterministic or known in advance, whereas the RSC 
system is normally known as a dynamic operation with a high level of uncertain data such as return rate, relevant costs, capacity, etc. [23,29-33]. To handle these imprecise data, stochastic techniques have been utilized [34-37]. However, using a stochastic method normally causes two main issues. Firstly, in some practical situations, collecting historical data is not enough to be used for uncertain parameters so it is quite a challenge to obtain the exact random distributions for these parameters. Secondly, a stochastic approach, used in previous studies, is normally used through different scenarios for modelling the uncertainties which might cause heavy computational burdens [38]. In this regard, to cope with the difficulties of stochastic methods, the fuzzy approach has been considered as a potential solution since it can solve imprecise data and different types of uncertainties at the same time with high computational efficiency [39]. A few studies [40-45] applied the fuzzy method to cope with supply chain management problems. Liang [42] proposed an interactive fuzzy multi-objective linear programming (FMOLP) to solve transportation problems with the minimization of the total distribution costs as well as the delivery time. FMOLP is the method that was developed to solve the multiple fuzzy linear programming by integrating the satisfaction of the decision-maker through the auxiliary variable $\mathrm{L}$. If the solution is $\mathrm{L}=1$, then each objective is fully satisfied; if $0<\mathrm{L}<1$, then all of the objectives are satisfied at the level of $\mathrm{L}$, and if $\mathrm{L}=0$, then none of the objectives are satisfied.

Furthermore, a supply chain system involves various activities across many organizations including suppliers, producers, retailers, and customers and due to this fact, there might be a high degree of risks involved across the supply chain [46,47]. According to Kumar et al. [48], risks in a supply chain operation can be considered as a potential variation from the initial plan, which can cause non-value-added activities at different stages. In supply chain risk management, the probability is defined as a measure of how often an unexpected event results in a potential loss while impact indicates the importance of the loss to the company [49]. Studies about risks in forward supply chains including demand risks, transportation risks, supply risks, delay risks, information risks, etc., were conducted by some researchers [50-53]. Note that risks are included in some forward supply chains but are rarely examined in RSC models.

According to the literature, existing models are insufficient to represent a practical e-waste RSC. To overcome this gap, this study aims to propose a multi-product, multitier RSC model for e-waste with risk costs incorporated. Risk factors in RSC models can lead to a significant impact on the entire RSC cost [54]. Risks normally occur during treatment processes and shipping activities due to many types of dangerous substances in e-waste $[55,56]$. In addition, most input data (e.g., all costs involved, the capacity of centers, return rate, risk factors, etc.) in the proposed model are considered as fuzzy in nature, which can handle uncertain parameters in real situations. The proposed model aims to minimize the total cost including collection, set-up, processing, shipping, disposal, and risk costs as well as the profit obtained from selling recovery materials and used items. Furthermore, the proposed model also applies an interactive fuzzy solution which can generate a practical and satisfactory solution to balance the conflict between minimizing the objective value and improving the degree of satisfaction constraints. This research will aid managers in the decision-making process particularly in selecting the optimal locations and the flow of materials. Compared to existing research, this proposed model suggests the actual total cost of the RSC network, which is closer to the reality as risks and uncertainties are simultaneously considered.

The body of this paper is organized as follows. The description of the problem is presented in Section 2, whereas the mathematical model is elaborated in Section 3. The proposed solution approach is reported in Section 4. In Section 5, an example with three scenarios is used to show the usefulness of the proposed model. Lastly, conclusions and some future directions are detailed in Section 6. 


\section{Problem Description}

The quantity of e-waste was nearly 50 million tons in 2018 [57], which has led to serious impacts on the environment and public health. With the designing of an e-waste RSC model, e-waste is classified and treated in proper centers which can recover raw materials and dispose of hazardous materials properly. Figure 1 presents a generic RSC network for e-waste, including four stages:

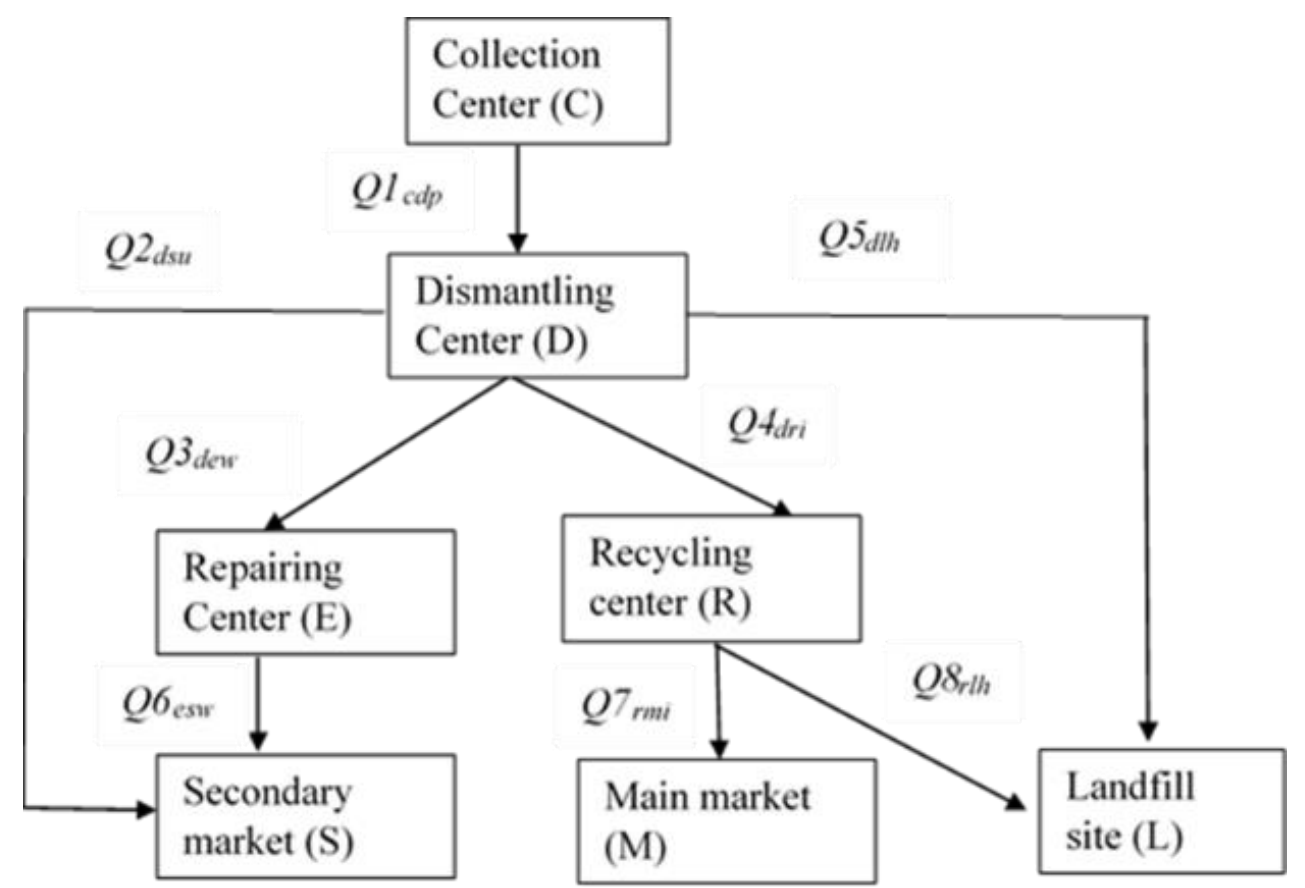

Figure 1. The generic e-waste reverse supply chain (RSC) network.

At the first stage, the end-of-life (EoL) products or discarded products from customers are gathered at collection centers (C). The customers can come from private households, company, retailers, etc., and they are able to drop-off their EoL products at collection centers. According to Yuksel [58], there are five common collection models used such as drop-off events, permanent collection points, curbside collection programs, retail collection, and non-profit collection. For example, curbside collection is a popular method to collect e-waste since it is regular, convenient, and available in urban areas to handle bulky waste for residents. On the other hand, drop-off events (one day or some days) can be a common way to collect e-waste, especially from non-urban areas where residents may not have easy to access to collection points. At the collection centers, inspection and sorting are conducted. These products are then transferred to dismantling centers (D) to dismantle them into different components and materials. Items in good condition are directly sent to secondary markets (S), whereas unrecoverable components or toxic waste are delivered to a landfill site (L) for special treatment. Ferrous metals and plastics are sent to recycling centers $(\mathrm{R})$ to be recycled, while non-working parts are transported to repairing centers (E). Lastly, recyclable substances and renewable parts are transferred to main markets (M) and secondary markets, respectively. Note that after processing at the main market, the materials can be returned to the forward supply chain.

Currently, the flow from (C) to (L) is usually under the operations of companies. Due to the imposing of regulations in several areas, for example, Europe and Japan, companies also must be in charge of handling their end-of-life products. For convenience purposes, users will return their end-of-life products at some specific locations or to company agents. The agents will wait until the quantities reach a certain level, then send them to the collection centers (C). 
From the company's perspective, the most challenging issue when designing the RSC is the problem of facility location. This would be one of the strategic variables. These facilities will serve to the end of the planning horizon. In this RSC model, the returned products, cost parameters, the capacity of centers, and a fraction of components reused or recycled are major sources of uncertainties. Strategic solutions must take account of these uncertainties. As a result, it is really challenging for decision-makers to determine a proper solution for this problem. In order to consider the effects of uncertainties in these parameters, fuzzy mixed integer programming approach is adopted in this proposed RSC framework to model and handle uncertainties in the e-waste RSC model. An interactive fuzzy approach is employed to create a balance between the objective value and the satisfaction of constraints of managers. This can support them to achieve the desired solution, while satisfying the company's constraints.

\section{A Developed Mathematical Model}

To establish an e-waste RSC model with uncertain parameters and risk factors, some assumptions are made in this research and are listed as below:

- The location of collection centers, the landfill site, and secondary and main markets are known in advance.

- The transportation cost is calculated depending on the product/part types and the distance travelled.

- The size of dismantling, repairing, and recycling centers is limited.

- Pessimistic and optimistic values for all imprecise parameters are identified as $10 \%$ less and more of the most likely value adopted from Özceylan and Paksoy [29].

The indices, decision variables, and parameters used in the formulation are listed below:

Indices:

$c$

$d$

$e$

$r$

$S$

$m$

$l$

$p$

$u$

$w$

$i$

$h$

$\widetilde{T p}$

Parameters:

set of collection centers, $c=1, \ldots, C$;

set of possible locations of dismantling centers, $d=1, \ldots, D$;

set of possible locations of repairing centers, $e=1, \ldots, E$;

set of possible locations of recycling centers, $r=1, \ldots, R$;

set of secondary markets, $s=1, \ldots, s$;

set of main markets, $m=1, \ldots, M$;

set of landfill site, $l=1, \ldots, L$;

set of used products, $p=1, \ldots, P$;

set of reusable parts, $u=1, \ldots, U$;

set of renewable parts, $w=1, \ldots, W$;

set of recycling materials, $i=1, \ldots, I$;

set of disposal parts, $h=1, \ldots, H$.

$\quad$ unit transportation cost of used product $p \in P$;

$\widetilde{T u}_{u} \quad$ unit transportation cost of reused component $u \in U$;

$\widetilde{T w}_{w} \quad$ unit transportation cost of renewable component $w \in W$;

$\widetilde{T} i_{i} \quad$ unit transportation cost of recycling material $i \in I$;

$\widetilde{T h}_{h} \quad$ unit transportation cost of disposal item $h \in H$;

$\widetilde{O d}_{p d} \quad$ unit processing cost of used product $p$ at dismantling center $d$;

$\widetilde{O e}$ we

$\widetilde{\mathrm{Or}} \mathrm{r}_{\text {ir }}$

$\widetilde{D}_{h}$

$\widetilde{C L} L_{p}$

$\widetilde{S d}_{d}$

$\widetilde{S} e_{e}$

$S \widetilde{r}_{r}$

$\widetilde{P u}_{u}$

$\widetilde{P} w_{w}$

$\widetilde{P} i_{i}$ unit processing cost of renewable component $w$ at repairing center $e$;

unit processing cost of recycling material $i$ at recycling center $r$;

unit disposal cost of disposal item $h$;

Unit collection cost of used product $p$ at collection area;

set-up cost of dismantling center $d$;

set-up cost of repairing center $e$;

set-up cost of recycling center $r$;

selling price per unit of reusable component $u$;

selling price per unit of renewable component $w$;

selling price per unit of recycling material $i$; 


\begin{tabular}{|c|c|}
\hline$B 1_{c d}$ & distance $c-d$; \\
\hline$B 2_{d s}$ & distance $d-s$; \\
\hline$B 3_{d e}$ & distance $d-e$; \\
\hline$B 4_{d r}$ & distance $d-r$; \\
\hline$B 5_{d l}$ & distance $d-l$; \\
\hline$B 6_{e s}$ & distance $e-s$; \\
\hline$B 7_{r m}$ & distance $r-m$; \\
\hline$B 8_{r l}$ & distance $r-l$; \\
\hline$\widetilde{A}_{p c}$ & the amount of used product $p$ at collection center $c$; \\
\hline$\widetilde{\varepsilon}_{\text {up }}^{\prime}$ & the average unit of reused item $u$ obtained from the used product $p$; \\
\hline$\widetilde{\varepsilon} \widetilde{2}_{w p}$ & the average unit of renewable item $w$ obtained from the used product $p$; \\
\hline$\widetilde{\varepsilon}_{i p}$ & the average unit of recycling material $i$ obtained from the used product $p$; \\
\hline$\widetilde{\varepsilon} 4_{h p}$ & the average unit of disposal item $h$ obtained from the used product $p$; \\
\hline$\widetilde{\beta}_{h}$ & the average fraction of disposal item $h$ obtained from recycling center; \\
\hline$\widetilde{\beta}_{i}$ & the average fraction of recycling material $i$ obtained at recycling center; \\
\hline$\widetilde{N} u_{u s}$ & maximum demand for reused item $u$ at secondary market $s$; \\
\hline$\widetilde{N w}_{w s}$ & maximum demand for renewable component $w$ at secondary market $s$; \\
\hline$\widetilde{N} i_{i m}$ & maximum demand for recycling material $i$ at main market $m$; \\
\hline$\widetilde{K d}_{p d}$ & maximum capacity of used product $p$ at dismantling center $d$; \\
\hline$\widetilde{K e}$ we & maximum capacity of renewable item $w$ at repairing center $e$; \\
\hline$\widetilde{K r}_{i r}$ & maximum capacity of recycling material $i$ at recycling center $r$; \\
\hline$\widetilde{K l}_{h l}$ & maximum capacity of disposal item $h$ at landfill site $l$; \\
\hline$\widetilde{P 1}{ }_{d}$ & the possibility of an unexpected event occurred at dismantling center $d$; \\
\hline$\widetilde{P 2_{e}}$ & the possibility of an unexpected event occurred at repairing center $e$; \\
\hline$\widetilde{P 3}_{r}$ & the possibility of an unexpected event occurred at recycling center $r$ \\
\hline$\widetilde{P 4}_{c d}$ & the possibility of an unexpected event occurred on the way $c-d$; \\
\hline$\widetilde{P 5} d s$ & the possibility of an unexpected event occurred on the way $d-s$; \\
\hline$\widetilde{P 6}_{d e}$ & the possibility of an unexpected event occurred on the way $d-e$; \\
\hline$\widetilde{P 7}_{d r}$ & the possibility of an unexpected event occurred on the way $d-r$; \\
\hline$\widetilde{P 8}_{d l}$ & the possibility of an unexpected event occurred on the way $d-l$; \\
\hline$\widetilde{P 9}_{e s}$ & the possibility of an unexpected event occurred on the way $e-s$; \\
\hline$\widetilde{P 10}_{r m}$ & the possibility of an unexpected event occurred on the way $r-m$; \\
\hline$\widetilde{P 11}_{r l}$ & the possibility of an unexpected event occurred on the way $r-l$; \\
\hline$\widetilde{I} 1_{d}$ & the impact of an unexpected event occurred at dismantling center $d$; \\
\hline$\widetilde{I 2}{ }_{e}$ & the impact of an unexpected event occurred at repairing center $e$; \\
\hline$\widetilde{I}_{r}$ & the impact of an unexpected event occurred at recycling center $r$ \\
\hline$\widetilde{I}_{c d}$ & the impact of an unexpected event occurred on the way $c-d$; \\
\hline$\widetilde{I}_{d s}$ & the impact of an unexpected event occurred on the way $d-s$; \\
\hline$\widetilde{I}_{d e}$ & the impact of an unexpected event occurred on the way $d-e$; \\
\hline$\widetilde{I}_{d r}$ & the impact of an unexpected event occurred on the way $d-r$; \\
\hline$\widetilde{I}_{d l}$ & the impact of an unexpected event occurred on the way $d-l$; \\
\hline$\widetilde{I}{ }_{e s}$ & the impact of an unexpected event occurred on the way $e-s$; \\
\hline$\widetilde{110} r m$ & the impact of an unexpected event occurred on the way $r-m$; \\
\hline$\widetilde{I 11_{r l}}$ & the impact of an unexpected event occurred on the way $r-l$. \\
\hline
\end{tabular}

Based on the four-tier RSC network, the main goal of the developed model is to suggest a mathematical model to minimize the overall cost through the entire RSC system. Total cost includes the sum of collection costs, set-up costs, processing costs, transportation costs, disposal costs, and risk costs and minus the profit obtained from selling used items and recovery materials (as seen in Equation (1)). The explanations and mathematical formulations of these components are presented in Equations (2)-(8).

Objective function

Total cost $(\mathrm{Z})=$ collection costs $(\mathrm{T} 1)+$ set-up costs $(\mathrm{T} 2)+$ processing costs $(\mathrm{T} 3)$

+ transportation costs (T4) + disposal costs (T5) + risk costs (T6)

- profit received from selling recovery materials and used items $(\mathrm{P})$ 
Collection costs (T1) are to collect EoL products from consumers, end-users, or retailers, which can be described in Equation (2).

$$
T 1=\sum_{c=1}^{C} \sum_{d=1}^{D} \sum_{p=1}^{P} Q 1_{c d p} \times \widetilde{C L}_{p}
$$

Note that $\widetilde{C L}_{p}$ is an uncertain parameter because it is challenging to estimate the collection cost exactly, which depends on the quality and volume of return products.

Set-up costs (T2) are the cost for building dismantling, recycling, and repairing centers, which can be calculated using Equation (3).

$$
T 2=\sum_{d=1}^{D} X_{d} \times \widetilde{S d}_{d}+\sum_{e=1}^{E} X_{e} \times \widetilde{S e}_{e}+\sum_{r=1}^{R} X_{r} \times \widetilde{S r}_{r}
$$

Processing costs at the treatment centers can be defined as Equation (4).

$$
T 3=\sum_{c=1}^{C} \sum_{d=1}^{D} \sum_{p=1}^{P} Q 1_{c d p} \times \widetilde{O d}_{p d}+\sum_{d=1}^{D} \sum_{e=1}^{E} \sum_{w=1}^{W} Q 3_{d e w} \times \widetilde{O e_{w e}}+\sum_{d=1}^{D} \sum_{r=1}^{R} \sum_{i=1}^{I} Q 4_{d r i} \times \widetilde{O r_{i r}}
$$

Transportation costs for shipping different types of parts from one center to another center are presented in Equation (5).

$$
\begin{array}{rl}
T 4=\sum_{c=1}^{C} \sum_{d=1}^{D} \sum_{p=1}^{P} & Q 1_{c d p} \times B 1_{c d} \times \widetilde{T p}_{p}+\sum_{d=1}^{D} \sum_{s=1}^{S} \sum_{u=1}^{U} Q 2_{d s u} \times B 2_{d s} \times \widetilde{T u}_{u} \\
& +\sum_{d=1}^{D} \sum_{e=1}^{E} \sum_{w=1}^{W} Q 3_{d e w} \times B 3_{d e} \times{\widetilde{T w_{w}}}_{w}+\sum_{d=1}^{D} \sum_{r=1}^{R} \sum_{i=1}^{I} Q 4_{d r i} \times B 4_{d r} \\
& \times{\widetilde{T l_{i}}}_{i}+\sum_{d=1}^{D} \sum_{l=1}^{L} \sum_{h=1}^{H} Q 5_{d l h} \times B 5_{d l} \times \widetilde{T h}_{h}+\sum_{e=1}^{S} \sum_{s=1}^{S} \sum_{w=1}^{W} Q 6_{e s w} \\
& \times B 6_{e s} \times \widetilde{T w}_{w}+\sum_{r=1}^{M} \sum_{m=1}^{I} \sum_{i=1}^{I} Q 7_{r m i} \times B 7_{r m} \times \widetilde{T}_{i} \\
& +\sum_{r=1}^{R} \sum_{l=1}^{L} \sum_{h=1}^{H} Q 8_{r l h} \times B 8_{r l} \times \widetilde{T h}_{h}
\end{array}
$$

The disposal costs for toxic substances can be found by Equation (6).

$$
T 5=\left(\sum_{d=1}^{D} \sum_{l=1}^{L} \sum_{h=1}^{H} Q 5_{d l h}+\sum_{r=1}^{R} \sum_{l=1}^{L} \sum_{h=1}^{H} Q 8_{r l h}\right) \times \widetilde{D}_{h}
$$

Risk costs (T6) are the cost incurred from the likelihood of any disruptive occurrences that might have an influence on the part of processing costs at treatment centers and transportation costs. In a supply chain system, the risk score is calculated by multiplying the probability and the loss of occurrence [59]. In this study, the first three terms of risk costs in Equation (7) represent the risk resulting from unexpected events such as accidents, technological issues, or less manpower during the treatment of EoL products or parts at dismantling, repairing, and recycling centers. The rest of Equation (7) presents the risk during transportation activities within an RSC network. 


$$
\begin{aligned}
& \text { T6 }=\sum_{c=1}^{C} \sum_{d=1}^{D} \sum_{p=1}^{P} Q 1_{c d p} \times \widetilde{O d}_{p d} \times \frac{\widetilde{P 1}_{d} \times \widetilde{I 1}_{d}}{\operatorname{Max}\left(\widetilde{P 1}_{d} \times \widetilde{I}_{d}\right)} \\
& +\sum_{d=1}^{D} \sum_{e=1}^{E} \sum_{w=1}^{W} Q 3_{d e w} \times \widetilde{O e_{w e}} \times \frac{\widetilde{P 2_{e}} \times \widetilde{I 2}_{e}}{\operatorname{Max}\left(\widetilde{P 2_{e}} \times \widetilde{I} 2_{e}\right)} \\
& +\sum_{d=1}^{D} \sum_{r=1}^{R} \sum_{i=1}^{I} Q 4_{d r i} \times \widetilde{O r}_{i r} \times \frac{\widetilde{P B}_{r} \times \widetilde{I B}_{r}}{\operatorname{Max}\left(\bar{P} 3_{r} \times \widetilde{I}_{r}\right)} \\
& +\sum_{c=1}^{C} \sum_{d=1}^{D} \sum_{p=1}^{P} Q 1_{c d p} \times B 1_{c d} \times \widetilde{T p}_{p} \times \frac{\widetilde{P 4}_{c d} \times \widetilde{I}_{c d}}{\operatorname{Max}\left(\widetilde{P} 4_{c d} \times \widetilde{I}_{c d}\right)} \\
& +\sum_{d=1}^{D} \sum_{s=1}^{S} \sum_{u=1}^{U} Q 2_{d s u} \times B 2_{d s} \times \widetilde{T u}_{u} \times \frac{\widetilde{P 5}_{d s} \times \widetilde{I}_{d s}}{\operatorname{Max}\left(\widetilde{P}_{d s} \times \widetilde{I}_{d s}\right)} \\
& +\sum_{d=1}^{D} \sum_{e=1}^{E} \sum_{w=1}^{W} Q 3_{d e w} \times B 3_{d e} \times \widetilde{T w}_{w} \times \frac{\widetilde{P 6}_{d e} \times \widetilde{I \sigma}_{d e}}{\operatorname{Max}\left(\tilde{P}_{d e} \times \widetilde{I}_{d e}\right)} \\
& +\sum_{d=1}^{D} \sum_{r=1}^{R} \sum_{i=1}^{I} Q 4_{d r i} \times B 4_{d r} \times \widetilde{T} i_{i} \times \frac{\widetilde{P}_{d r} \times \widetilde{I}_{d r}}{\operatorname{Max}\left(\widetilde{P} 7_{d r} \times \widetilde{I}_{d r}\right)} \\
& +\sum_{d=1}^{D} \sum_{l=1}^{L} \sum_{h=1}^{H} Q 5_{d l h} \times B 5_{d l} \times \widetilde{T h}_{h} \times \frac{\widetilde{P 8}_{d l} \times \widetilde{I}_{d l}}{\operatorname{Max}\left(\widetilde{P 8_{d l}} \times \widetilde{I}_{d l}\right)} \\
& +\sum_{e=1}^{E} \sum_{s=1}^{S} \sum_{w=1}^{W} Q 6_{e s w} \times B 6_{e s} \times \widetilde{T w} w_{w} \times \frac{\widetilde{P g}_{e s} \times \widetilde{I}_{e s}}{\operatorname{Max}\left(\widetilde{P 9_{e s}} \times \widetilde{I}_{e s}\right)} \\
& +\sum_{r=1}^{R} \sum_{m=1}^{M} \sum_{i=1}^{I} Q 7_{r m i} \times B 7_{r m} \times \widetilde{T}_{i} \times \frac{\widetilde{P 10_{r m}} \times \widetilde{10}_{r m}}{\operatorname{Max}\left(\overline{P 10_{r m}} \times \widetilde{I 10} 0_{r m}\right)} \\
& +\sum_{r=1}^{R} \sum_{l=1}^{L} \sum_{h=1}^{H} Q 8_{r l h} \times B 8_{r l} \times \widetilde{T h}_{h} \times \frac{{\widetilde{P 11_{r l}}} \times \widetilde{I 1}_{r l}}{\operatorname{Max}\left(\overline{\left.P 11_{r l} \times I 11_{r l}\right)}\right.}
\end{aligned}
$$

Profit from selling used items and recovery materials can be calculated using Equation (8). $P=\sum_{d=1}^{D} \sum_{s=1}^{S} \sum_{u=1}^{U} Q 2_{d s u} \times \widetilde{P u}_{u}+\sum_{e=1}^{E} \sum_{s=1}^{S} \sum_{w=1}^{W} Q 6_{e s w} \times \widetilde{P w}_{w}+\sum_{r=1}^{R} \sum_{m=1}^{M} \sum_{i=1}^{I} Q 7_{r m i} \times \widetilde{P} i_{i}$

Subject to

$$
\begin{gathered}
\sum_{d=1}^{D} Q 1_{c d p}=\widetilde{A}_{p c} \\
\sum_{p=1}^{P}\left(\widetilde{\varepsilon} 1_{u p} \times \sum_{c=1}^{C} Q 1_{c d p}\right)=\sum_{s=1}^{S} Q 2_{d s u}, \forall d, u \\
\sum_{p=1}^{P}\left(\widetilde{\varepsilon 2}_{w p} \times \sum_{c=1}^{C} Q 1_{c d p}\right)=\sum_{e=1}^{E} Q 3_{d e w}, \forall d, w \\
\sum_{p=1}^{P}\left(\widetilde{\varepsilon}_{i p} \times \sum_{c=1}^{C} Q 1_{c d p}\right)=\sum_{r=1}^{R} Q 4_{d r i}, \forall d, i \\
\sum_{p=1}^{P}\left(\widetilde{\varepsilon}_{h p} \times \sum_{c=1}^{C} Q 1_{c d p}\right)=\sum_{l=1}^{L} Q 5_{d l h}, \forall d, h \\
\sum_{d=1}^{D} Q 3_{d e w}=\sum_{s=1}^{S} Q 6_{e s w}, \forall e, w \\
\sum_{m=1}^{M} Q 7_{r m i}=\left(\widetilde{\beta}_{i} \times \sum_{d=1}^{D} Q 4_{d r i}\right), \forall i, r \\
\sum_{l=1}^{L} Q 8_{r l h}=\left(\widetilde{\beta}_{h} \times \sum_{d=1}^{D} \sum_{i=1}^{I} Q 4_{d r i}\right), \forall r, h
\end{gathered}
$$




$$
\begin{gathered}
\sum_{c=1}^{C} Q 1_{c d p} \leq X_{d} \times \widetilde{K d}_{d p}, \forall d, p \\
\sum_{d=1}^{D} Q 3_{d e w} \leq X_{e} \times \widetilde{K e_{w e}}, \forall e, w \\
\sum_{d=1}^{D} Q 4_{d r i} \leq X_{r} \times \widetilde{K r_{i r}}, \forall i, r \\
\sum_{d=1}^{D} Q 5_{d l h}+\sum_{r=1}^{R} Q 8_{r l h} \leq \widetilde{K l_{i r}}, \forall l, h \\
\sum_{d=1}^{D} Q 2_{d s u} \leq \widetilde{N u_{u s}}, \forall u, s \\
\sum_{e=1}^{E} Q 6_{e s w} \leq \widetilde{N w_{w s s}, \forall w, s} \\
\sum_{r=1}^{R} Q 7_{r m i} \leq \widetilde{N i_{i m}}, \forall i, m \\
X_{d}, X_{e}, X_{r}: \text { binary } \\
Q 1_{c d p}, Q 2_{d s u}, Q 3_{d e w w}, Q 4_{d r i}, Q 5_{d l h}, Q 6_{e s w}, Q 7_{r m i}, Q 8_{r l h} \geq 0
\end{gathered}
$$

Constraint (9) is to make sure that all used products are picked up at collection centers. Constraints (10)-(13) represent the results of disassembly processes at dismantling centers. In other words, a returned product at a dismantling center is broken down into different components or materials through a mix of manual and automated process, which are delivered to appropriate centers (e.g., repairing centers, recycling centers, secondary markets, and landfill sites). Constraint (10) stipulates that the flow of directly reusable components at dismantling centers is equal to the incoming flow of these components at secondary markets. Constraint (11) indicates that the flow of faulty components at dismantling centers is equal to the incoming flow of these components at repairing centers. Constraint (12) ensures that the flow of recycling materials at dismantling centers is equal to the incoming flow of these materials at recycling centers. Constraint (13) makes sure that the flow of disposal items at dismantling centers is equal to the incoming flow of these items at landfill sites.

Constraints (14)-(16) ensure flow balance between different centers. Constraint (14) implies that the flow of repaired components is equal to the incoming flow of these components to secondary markets. Constraints (15) and (16) make sure that the flow of recyclable components multiplied by operation efficiency $\left(\widetilde{\beta}_{i}, \widetilde{\beta}_{h}\right)$ at recycling centers is equal to the incoming flow at main markets and the landfill site, respectively. Constraints (17)-(20) represent the capacity restrictions of different centers. Constraint (17) guarantees that the number of used products is not greater than the maximum capacity of dismantling centers. Constraint (18) shows that the number of faulty components is not greater than the maximum capacity of repairing centers. Constraint (19) ensures that the number of recycling materials does not exceed the maximum capacity of recycling centers. Constraint (20) shows that the number of disposal items does not exceed the maximum capacity of landfill sites.

Constraints (21)-(23) indicate that the number of used items, recovery materials, and renewable components is not greater than the need for secondary and main markets. Constraints (24) and (25) present binary and integer variables, respectively. 


\section{Proposed Approach}

This section demonstrates how fuzzy mixed integer programming (FMILP) is constructed to deal with risk and uncertain factors in the e-waste RSC. In the real world, most input parameters are normally decided through historical data and experts' knowledge, which is a key challenge in an RSC network design [30]. The reason is that for some practical applications, there is not adequate historical data and it is difficult for decision-makers to determine these parameters exactly in RSC operations. Thus, some studies adopted a stochastic program based on different scenarios to address the issue, which leads to heavy computation [23].

The input data of the RSC for e-waste are considered as unknown parameters (i.e., the number of returns, fixed cost, transportation cost, disposal cost, risk cost, and the capability of centers) because RSC is recognized as a dynamic system with a lot of uncertain factors involved. In most existing research, these parameters are assumed as deterministic and known in advance. This is not true in real-life applications, which always affects the performance of the RSC network. Therefore, the proposed model aims to consider these parameters by triangular fuzzy numbers. To handle these uncertain parameters, an FMILP is adopted. There are two main steps for applying the solution approach. In the first step, the FMILP model is transformed into an auxiliary model [60]. The second step is to implement an interactive fuzzy approach to find the optimal solution.

\subsection{Converting the FMILP Model to the Auxiliary Crisp Model}

Jiménez et al.'s approach can be effectively applied several kinds of fuzzy numbers such as trapezoidal, triangular, and either linear or nonlinear problems. In addition, this method is generally superior to address fuzzy linear problems because it still maintains the linearity of the original model.

As the first step, it is assumed that a triangular fuzzy number $\widetilde{a}=\left(a_{1}, a_{2}, a_{3}\right)$ is given, where $a_{1}$ represents the pessimistic value, $a_{2}$ is the most likely value, and $a_{3}$ presents the optimistic value of the triangular fuzzy number.

The triangular membership function of $\widetilde{a}$ can be described as below:

$$
\mu_{\widetilde{a}}(x)=\left\{\begin{array}{cc}
f_{a}(x)=\frac{x-a_{1}}{a_{2}-a_{1}}, & \text { if } a_{1} \leq x \leq a_{2} \\
1 & \text { if } x=a_{2} \\
g_{a}(x)=\frac{a_{3}-x}{a_{3}-a_{2}} & \text { if } a_{2} \leq x \leq a_{3} \\
0 & \text { otherwise }
\end{array}\right.
$$

Based on Heilpern's [61] approach, $E I(\widetilde{a})$ is considered as the expected interval of a triangular number $\widetilde{a}$, and the expected value of a triangular number $\widetilde{a}$ is denoted as $E V(\widetilde{a})$ can be computed in Equations (27) and (28).

$$
\begin{gathered}
E I(\widetilde{a})=\left[E_{1}^{a}, E_{2}^{a}\right]=\left[\int_{0}^{1} f_{a}^{-1}(x) d x, \int_{0}^{1} g_{a}^{-1}(x) d x\right]=\left[\frac{1}{2}\left(a_{1}+a_{2}\right), \frac{1}{2}\left(a_{2}+a_{3}\right)\right] \\
E V(\widetilde{a})=\frac{E_{1}^{a}+E_{2}^{a}}{2}=\frac{a_{1}+2 a_{2}+a_{3}}{4}
\end{gathered}
$$

According to [60], if there are two fuzzy numbers $\widetilde{a}$ and $\widetilde{b}$, and $\widetilde{a}$ is bigger than $\widetilde{b}$, the membership function $\mu_{M}$ can be defined by:

$$
\mu_{M}(\widetilde{a}, \widetilde{b})=\left\{\begin{array}{cc}
0 & \text { if } E_{2}^{a}-E_{1}^{b}<0 \\
\frac{E_{2}^{a}-E_{1}^{b}}{E_{2}^{a}-E_{1}^{b}-\left(E_{1}^{a}-E_{2}^{b}\right)} & \text { if } 0 \in\left[E_{1}^{a}-E_{2}^{b}, E_{2}^{a}-E_{1}^{b}\right] \\
1 & \text { if } E_{1}^{a}-E_{2}^{b}>0
\end{array}\right.
$$


In this case, $\mu_{M}(\widetilde{a}, \widetilde{b}) \geq \alpha$ which indicates that $\widetilde{b}$ is less than $\widetilde{a}$ at least in a degree $\alpha$. When $\widetilde{a}$ and $\widetilde{b}$ are indifferent in a degree $\alpha$, it is noted $\frac{\alpha}{2} \leq \mu_{M}(\widetilde{a}, \widetilde{b}) \leq 1-\frac{\alpha}{2}$ [62]. Hence, a fuzzy model can be presented as follows:

$$
\operatorname{Min} w=\widetilde{c}^{T} x
$$

Subject to

$$
\begin{gathered}
\widetilde{a}_{i} x \geq \widetilde{b}_{i}, i=1, \ldots, k \\
\widetilde{a}_{i} x=\widetilde{b}_{i}, i=k+1, \ldots n \\
x \geq 0
\end{gathered}
$$

where $\widetilde{c}^{T}$ is a fuzzy vector.

According to Equations (29) and (30), the two above constraints $\widetilde{a}_{i} x \geq \widetilde{b}_{i}$ and $\widetilde{a}_{i} x=\widetilde{b}_{i}$ can be converted into the equivalent constraints, respectively, in Equations (31) and (32).

$$
\begin{gathered}
\frac{E_{2}^{a_{i} x}-E_{1}^{b_{i}}}{E_{2}^{a_{i} x}-E_{1}^{a_{i} x}+E_{2}^{b_{i}}-E_{1}^{b_{i}}} \geq \alpha, i=1, \ldots, k \\
\frac{\alpha}{2} \leq \frac{E_{2}^{a_{i} x}}{E_{2}^{a_{i} x}-E_{1}^{a_{i} x}+E_{2}^{b_{i}}-E_{1}^{b_{i}}} \leq 1-\frac{\alpha}{2}, i=k+1, \ldots, n
\end{gathered}
$$

According to [60], with various feasible solutions of $\mathrm{x}$, the feasible solution $x_{0}$ is selected based on an $\alpha$-acceptable optimal solution of the model of Equation (30) in the case that Equation (33) is achieved:

$$
\widetilde{c}^{T} x \geq{ }_{\frac{1}{2}} \widetilde{c}^{T} x_{0}
$$

Finally, the fuzzy model in Equation (30) can be converted into a crisp $\alpha$-parametric model as follows:

$$
\begin{aligned}
& \operatorname{Min} E V(\widetilde{c})^{T} x \\
& {\left[(1-\alpha) E_{2}^{a_{i}}+\alpha E_{1}^{a_{i}}\right] x \geq \alpha E_{2}^{b_{i}}+(1-\alpha) E_{1}^{b_{i}}, i=1, \ldots, k} \\
& {\left[\left(1-\frac{\alpha}{2}\right) E_{2}^{a_{i}}+\frac{\alpha}{2} E_{1}^{a_{i}}\right] x \geq \frac{\alpha}{2} E_{2}^{b_{i}}+\left(1-\frac{\alpha}{2}\right) E_{1}^{b_{i}}, i=k+1, \ldots, n} \\
& {\left[\frac{\alpha}{2} E_{2}^{a_{i}}+\left(1-\frac{\alpha}{2}\right) E_{1}^{a_{i}}\right] x \leq\left(1-\frac{\alpha}{2}\right) E_{2}^{b_{i}}+\frac{\alpha}{2} E_{1}^{b_{i}}, i=k+1, \ldots, n}
\end{aligned}
$$

Next, an interactive fuzzy approach in the following section is presented to deal with the crisp model.

\subsection{Interactive Fuzzy}

To obtain the optimal objective function value, the decision-maker (DM) has to balance the two contrary elements: to enhance the objective function value and to improve the satisfaction of constraints. To be specific, if the satisfaction of constraints is at a higher level, the feasible solution is small, and as a result, the optimal value of the objective function is worse [30]. To address this issue, an interactive method [60] aims to find the optimal solution.

Assume that $x^{0}\left(\alpha_{m}\right)$ will be $\alpha_{m}$ which is an acceptable optimal solution, where $\alpha=\alpha_{m}$. The objective values with corresponding fuzzy numbers can be computed by using Equation (34) as $\widetilde{z}^{0}\left(\alpha_{m}\right)=\widetilde{c}^{T} x^{0}\left(\alpha_{m}\right)$. The discrete values of $\alpha_{m}$ in the set $\mathrm{F}$ is presented as below:

$$
F=\left\{\alpha_{m}=\alpha_{0}+0.1 m \mid m=0,1, \ldots, \frac{1-\alpha_{0}}{0.1}\right\} \subset[0,1]
$$

where $\alpha_{0}$ is the minimum feasibility degree and $\alpha$ is an arbitrary value selected by DM, $\alpha_{0} \leq \alpha \leq 1$. 
There are 11 scales of $\alpha$ with the different linguistic degrees of the DM in the fuzzy process, shown in Table 1 [30].

Table 1. Eleven scales of $\alpha$ with different linguistic levels of decision maker (DM).

\begin{tabular}{|c|c|}
\hline$\alpha$ Values & Different Linguistic Levels of DM \\
\hline$\alpha=0$ & Solution is not accepted \\
\hline$\alpha=0.1$ & Solution is not practically accepted \\
\hline$\alpha=0.2$ & Solution is almost not accepted \\
\hline$\alpha=0.3$ & Solution is very not accepted \\
\hline$\alpha=0.4$ & Solution is quite not accepted \\
\hline$\alpha=0.5$ & Solution is not accepted \\
\hline$\alpha=0.6$ & Solution is quite accepted \\
\hline$\alpha=0.7$ & Solution is very accepted \\
\hline$\alpha=0.8$ & Solution is almost accepted \\
\hline$\alpha=0.9$ & Solution is practically accepted \\
\hline$\alpha=1$ & Solution is completely accepted \\
\hline
\end{tabular}

Once different values of $\widetilde{z}^{0}\left(\alpha_{m}\right)$ are determined, the DM will calculate a value goal in between $\underline{G}$ and $\bar{G}$, which are the minimum and maximum values, respectively. The DM is totally satisfied as $z=\underline{G}$, whilst he/she is totally dissatisfied as $z=\bar{G}$. The membership function of $\widetilde{G}$ shown as $\mu_{\widetilde{G}}(z)$ and the degree of satisfaction of the fuzzy goal $\widetilde{G}$ by each $\widetilde{z}^{0}\left(\alpha_{m}\right)$ are, respectively, computed using Equations (36) and (37):

$$
\begin{gathered}
\mu_{\widetilde{G}}(z)=\left\{\begin{array}{l}
1 z \leq \underline{G} \\
\frac{z-\bar{G}}{\underline{G}-\bar{G}} \quad \underline{G}<z<\bar{G} \\
0 z \geq \bar{G}
\end{array}\right. \\
X_{\widetilde{G}}\left(\widetilde{z}^{0}(\alpha)\right)=\frac{\int_{-\infty}^{+\infty} \mu_{\widetilde{z}^{0}(\alpha)}(z) \cdot \mu_{\widetilde{G}}(z) d z}{\int_{-\infty}^{+\infty} \mu_{\tilde{z}^{0}(\alpha)}(z) d z}
\end{gathered}
$$

Finally, a balancing solution with different $\alpha_{m}$ between the level of satisfaction and the feasibility level of constraints is computed by:

$$
\mu_{\widetilde{H}}\left(x^{0}\left(\alpha_{m}\right)\right)=\alpha_{m} * X_{\widetilde{G}}\left(\widetilde{z}^{0}\left(\alpha_{m}\right)\right)
$$

Note that ${ }^{*}$ is defined as a t-norm (the minimum value). The optimal solution $x^{*}$ is calculated as:

$$
\mu_{\widetilde{H}}\left(x^{*}\right)=\max _{\alpha_{m} \in F}\left\{\alpha_{m} * X_{\widetilde{G}}\left(\widetilde{z}^{0}\left(\alpha_{m}\right)\right)\right\}
$$

Equation (39) aims to suggest the best solution for DM to be selected and it is the highest membership level.

\section{An Illustrative Example}

This section aims to use an illustrative example to validate the proposed FMILP model, which is a multi-product, multi-tier RSC considering risk costs and an uncertain environment.

A dataset is randomly generated in a reasonable manner and based on published papers $[13,17,21,63,64]$. A summary of these data is presented in Table A1, Appendix A. It is assumed that there are two types of used products [21] and the components of each product are shown in Table 2. The size of the proposed problem is provided in Table 3. The average percentage of recycling materials and disposal items generated from recycling centers is assumed as shown in Table 4, whereas the quantity of used products at the collection areas is given in Table 5. The distance between centers is assumed to be as presented in Table 6, whilst the unit transportation costs, processing costs, collection costs, disposal costs, and 
set-up costs are provided in Tables 7-10. The profits from selling reusable, renewable, and recovery items are given in Table 11. The maximum capacities at centers are presented in Tables 12 and 13. It is also assumed that the probability and the impact of accident occurrence at treatment centers and shipping activities are in the range of 1 (lowest) to 10 (highest) adopted from [50] and provided in Tables 14 and 15. For example, the quantity of the used product $\widetilde{A}_{11}=(288 ; 320 ; 352)$ in column 1 of Table 5 represents the pessimistic, most likely, and optimistic values of the used product that is received. The rest of the uncertain parameters also address this in the same way.

Table 2. Components of each product.

\begin{tabular}{ccc}
\hline & 1st Used Product (Unit) & 2nd Used Product (Unit) \\
\hline Reuse components & 1 & 1 \\
Renewable components & 1 & 1 \\
Recycling materials & 3 & 2 \\
Disposal items & 4 & 3 \\
\hline
\end{tabular}

Table 3. The size for centers, products, and components.

\begin{tabular}{cccccccccccc}
\hline $\boldsymbol{C}$ & $\boldsymbol{D}$ & $\boldsymbol{E}$ & $\boldsymbol{R}$ & $\boldsymbol{S}$ & $\boldsymbol{M}$ & $\boldsymbol{L}$ & $\boldsymbol{P}$ & $\boldsymbol{U}$ & $\boldsymbol{W}$ & $\boldsymbol{I}$ & $\boldsymbol{H}$ \\
\hline 2 & 2 & 2 & 2 & 2 & 2 & 1 & 2 & 2 & 2 & 5 & 7 \\
\hline
\end{tabular}

Table 4. The average percentage of recycling materials and disposal items generated from recycling centers.

\begin{tabular}{cc}
\hline$\tilde{\beta}_{i}$ & $\tilde{\beta}_{h}$ \\
\hline$(0.78,0.8,0.82)$ & $(0.18,0.2,0.22)$ \\
\hline
\end{tabular}

Table 5. The amount of used products at collection sites (unit).

\begin{tabular}{ccc}
\hline & $\tilde{A}_{1 c}$ & $\tilde{A}_{2 c}$ \\
\hline$c=1$ & $(288,320,352)$ & $(252,280,308)$ \\
$c=2$ & $(333,370,407)$ & $(297,330,363)$ \\
\hline
\end{tabular}

Table 6. Distance between centers (km).

\begin{tabular}{ccccccccccccccccc}
\hline Dist. & $\boldsymbol{C}_{\mathbf{1}}$ & $\boldsymbol{C}_{\mathbf{2}}$ & $\boldsymbol{E}_{\mathbf{1}}$ & $\boldsymbol{E}_{\mathbf{2}}$ & $\boldsymbol{R}_{\mathbf{1}}$ & $\boldsymbol{R}_{\mathbf{2}}$ & $\boldsymbol{L}_{\mathbf{1}}$ & $\boldsymbol{S}_{\mathbf{1}}$ & $\boldsymbol{S}_{\mathbf{2}}$ & Dist. & $\boldsymbol{S}_{\mathbf{1}}$ & $\boldsymbol{S}_{\mathbf{2}}$ & Dist. & $\boldsymbol{M}_{\mathbf{1}}$ & $\boldsymbol{M}_{\mathbf{2}}$ & $\boldsymbol{L}_{\mathbf{1}}$ \\
\hline$D_{1}$ & 18 & 20 & 34 & 36 & 39 & 37 & 23 & 22 & 24 & $E_{1}$ & 23 & 26 & $R_{1}$ & 23 & 27 & 24 \\
$D_{2}$ & 22 & 26 & 25 & 26 & 40 & 42 & 29 & 23 & 25 & $E_{2}$ & 24 & 24 & $R_{2}$ & 25 & 28 & 26 \\
\hline
\end{tabular}

Table 7. The unit transportation cost (us dollar).

\begin{tabular}{|c|c|c|c|c|c|}
\hline \multicolumn{2}{|c|}{ Products } & \multicolumn{2}{|c|}{ Reusable Items } & \multicolumn{2}{|c|}{ Renewable Items } \\
\hline $\begin{array}{c}\widetilde{T p}_{1} \\
(1.08,1.2,1.32)\end{array}$ & $\begin{array}{c}\widetilde{T p_{2}} \\
(0.9,1,1.1)\end{array}$ & $\begin{array}{c}\widetilde{T u_{1}} \\
(0.63,0.7,0.77)\end{array}$ & $\begin{array}{c}\widetilde{\mathrm{Tu}}{ }_{2} \\
(0.72,0.8,0.88)\end{array}$ & $\begin{array}{c}\widetilde{T w}_{1} \\
(0.45,0.5,0.55)\end{array}$ & $\begin{array}{c}\widetilde{T w}_{2} \\
(0.36,0.4,0.44)\end{array}$ \\
\hline \multicolumn{6}{|c|}{ Recycling materials } \\
\hline $\begin{array}{c}\widetilde{T} i_{1} \\
(0.27,0.3,0.33)\end{array}$ & $\begin{array}{c}\widetilde{T} i_{2} \\
(0.27,0.3,0.33)\end{array}$ & $\begin{array}{c}\widetilde{T} i_{3} \\
(0.18,0.2,0.22)\end{array}$ & $\begin{array}{c}\widetilde{T} i_{4} \\
(0.18,0.2,0.22)\end{array}$ & $\begin{array}{c}\widetilde{T} i_{5} \\
(0.24,0.3,0.33)\end{array}$ & \\
\hline \multicolumn{6}{|c|}{ Disposal items } \\
\hline $\begin{array}{c}\widetilde{T h}_{1} \\
(0.36,0.4,0.44) \\
\widetilde{T h} \\
(0.18,0.2,0.22)\end{array}$ & $\begin{array}{c}\widetilde{T h}_{2} \\
(0.36,0.4,0.44)\end{array}$ & $\begin{array}{c}\widetilde{T h}_{3} \\
(0.27,0.3,0.33)\end{array}$ & $\begin{array}{c}\widetilde{T h}_{4} \\
(0.45,0.5,0.55)\end{array}$ & $\begin{array}{c}\widetilde{T h}_{5} \\
(0.18,0.2,0.22)\end{array}$ & $\begin{array}{c}\widetilde{T h}_{6} \\
(0.36,0.4,0.44)\end{array}$ \\
\hline
\end{tabular}


Table 8. Collection and disposal costs per unit (us dollar).

\begin{tabular}{ccccc}
\hline \multicolumn{3}{c}{ Collection Cost } \\
\hline & $\widetilde{C L}_{1}$ & & \\
& $(1.8,2,2.2)$ & $\widetilde{C L}_{2}$ \\
& & $(0.9,1,1.1)$ \\
\hline$\widetilde{D}_{1}$ & $\widetilde{D}_{2}$ & $\widetilde{D}_{3}$ & $\widetilde{D}_{4}$ & $\widetilde{D}_{5}$ \\
$(1.26,1.4,1.54)$ & $(1.08,1.2,1.32)$ & $(1.8,2,2.2)$ & $(0.9,1,1.1)$ & $(1.26,1.4,1.54)$ \\
\hline & $\widetilde{D}_{6}$ & & $\widetilde{D}_{7}$ \\
& $(1.08,1.2,1.32)$ & & $(1.17,1.3,1.43)$ \\
\hline
\end{tabular}

Table 9. Processing cost of dismantling, repairing, and recycling centers (us dollar).

\begin{tabular}{|c|c|c|c|c|c|}
\hline \multicolumn{3}{|c|}{ Used Products } & & \multicolumn{2}{|c|}{ Reusable Items } \\
\hline & $\widetilde{O d} d_{1 d}$ & $\widetilde{\mathrm{Od}}_{2 d}$ & & $\widetilde{\mathrm{O} e}_{1 e}$ & $\widetilde{O}_{2 e}$ \\
\hline \multirow{4}{*}{$\begin{array}{l}d=1 \\
d=2\end{array}$} & $(4.5,5,5.5)$ & $(4.5,5,5.5)$ & $e=1$ & $(1.8,2,2.2)$ & $(2.7,3,3.3)$ \\
\hline & $(3.6,4,4.4)$ & $(2.7,3,3.3)$ & $e=2$ & $(3.6,4,4.4)$ & $(2.7,3,3.3)$ \\
\hline & \multicolumn{5}{|c|}{ Recycling Materials } \\
\hline & $\widetilde{O r}_{1 r}$ & $\widetilde{O r}_{2 r}$ & $\widetilde{\mathrm{Or}}_{3 r}$ & $\widetilde{O r}_{4 r}$ & $\widetilde{O r}_{5 r}$ \\
\hline$r=1$ & $(2.7,3,3.3)$ & $(1.8,2,2.2)$ & $(1.8,2,2.2)$ & $(0.9,1,1.1)$ & $(1.8,2,2.2)$ \\
\hline$r=2$ & $(1.8,2,2.2)$ & $(1.8,2,2.2)$ & $(2.7,3,3.3)$ & $(1.8,2,2.2)$ & $(2.7,3,3.3)$ \\
\hline
\end{tabular}

Table 10. Set up cost for constructing dismantling, repairing, and recycling centers (us dollar).

\begin{tabular}{cccc}
\hline No & $\widetilde{\boldsymbol{S d}}_{\boldsymbol{d}}$ & $\widetilde{\boldsymbol{S} \boldsymbol{e}_{\boldsymbol{e}}}$ & $\widetilde{\boldsymbol{S}}_{\boldsymbol{r}}$ \\
\hline 1 & $(1260,1400,1540)$ & $(1215,1350,1485)$ & $(1170,1300,1430)$ \\
2 & $(378,1300,462)$ & $(1242,1380,1518)$ & $(1206,1340,1474)$ \\
\hline
\end{tabular}

Table 11. Profit from selling reusable, renewable, recovery items per unit (us dollar).

\begin{tabular}{ccccc}
\hline$\widetilde{P u_{1}}$ & $\widetilde{P u_{2}}$ & $\widetilde{P w_{1}}$ & $\widetilde{P w_{2}}$ & \\
\hline$(2.7,3,3.3)$ & $(3.6,4,4.4)$ & $(1.8,2,2.2)$ & $(2.7,3,3.3)$ & \\
\hline$\widetilde{P} i_{1}$ & $\widetilde{P} i_{2}$ & $\widetilde{P} i_{3}$ & $\widetilde{P} i_{4}$ & $\widetilde{P} i_{5}$ \\
\hline$(2.7,3,3.3)$ & $(3.6,4,4.4)$ & $(1.8,2,2.2)$ & $(1.8,2,2.2)$ & $(2.7,3,3.3)$ \\
\hline
\end{tabular}

Table 12. Maximum capacity at dismantling, repairing, and recycling centers (unit).

\begin{tabular}{|c|c|c|c|c|c|}
\hline & $\widetilde{K d} d_{1 d}$ & $\widetilde{K d}_{2 d}$ & & $\widetilde{K e}_{1 e}$ & $\widetilde{K e}_{2 e}$ \\
\hline$d=1$ & $(450,500,550)$ & $(540,600,660)$ & $e=1$ & $(810,900,990)$ & $(990,1100,1210)$ \\
\hline \multirow[t]{2}{*}{$d=2$} & $(360,400,440)$ & $(450,500,550)$ & $e=2$ & $(1080,1200,1320)$ & $(900,1000,1100)$ \\
\hline & $\widetilde{\boldsymbol{K}} \boldsymbol{r}_{1 r}$ & $\widetilde{K}_{2 r}$ & $\widetilde{K}_{3 r}$ & $\widetilde{K}_{4 r}$ & $\widetilde{K}_{5 r}$ \\
\hline$r=1$ & $(360,400,440)$ & $(540,600,660)$ & $(450,500,550)$ & $(540,600,660)$ & $(630,700,770)$ \\
\hline \multirow[t]{2}{*}{$r=2$} & $(360,400,440)$ & $(270,300,330)$ & $(450,500,550)$ & $(360,400,440)$ & $(450,500,550)$ \\
\hline & $\widetilde{K} l_{1 l}$ & $\widetilde{K l}_{2 l}$ & $\widetilde{K l}_{3 l}$ & $\widetilde{K} l_{4 l}$ & $\widetilde{K l}_{5 l}$ \\
\hline \multirow[t]{2}{*}{$l=1$} & $(900,1000,1100)$ & $(990,1100,1210)$ & $(720,800,880)$ & $(810,900,990)$ & $(1080,1200,1320)$ \\
\hline & $\widetilde{K l}_{6 l}$ & $\widetilde{K l} l_{7 l}$ & & & \\
\hline$l=1$ & $(1260,1400,1540)$ & $(1080,1200,1320)$ & & & \\
\hline
\end{tabular}


Table 13. Maximum demand at secondary and main markets (unit).

\begin{tabular}{cccccc}
\hline & $\widetilde{N u_{1 s}}$ & $\widetilde{N u}_{2 s}$ & $\widetilde{N w}_{1 s}$ & $\widetilde{N w}_{2 s}$ \\
\hline$s=1$ & $(630,700,770)$ & $(810,900,990)$ & $(1080,1200,1320)$ & $(1350,1500,1650)$ \\
$s=2$ & $(900,1000,1100)$ & $(297,330,363)$ & $(1170,1300,1430)$ & $(900,1000,1100)$ & $\widetilde{N i}_{4 m}$ \\
\hline$\widetilde{N i}_{1 m}$ & $\widetilde{N i} i_{2 m}$ & $\widetilde{N i} i_{3 m}$ & $(720,800,880)$ & $(900,1000,1100)$ \\
\hline$m=1$ & $(1260,1400,1540)$ & $(1350,1500,1650)$ & $(1170,1300,1430)$ & $(100)$ & $(1080,1200,1320)$ \\
\hline
\end{tabular}

Table 14. Probability of accident occurrence and the impact at dismantling, repairing, and recycling centers.

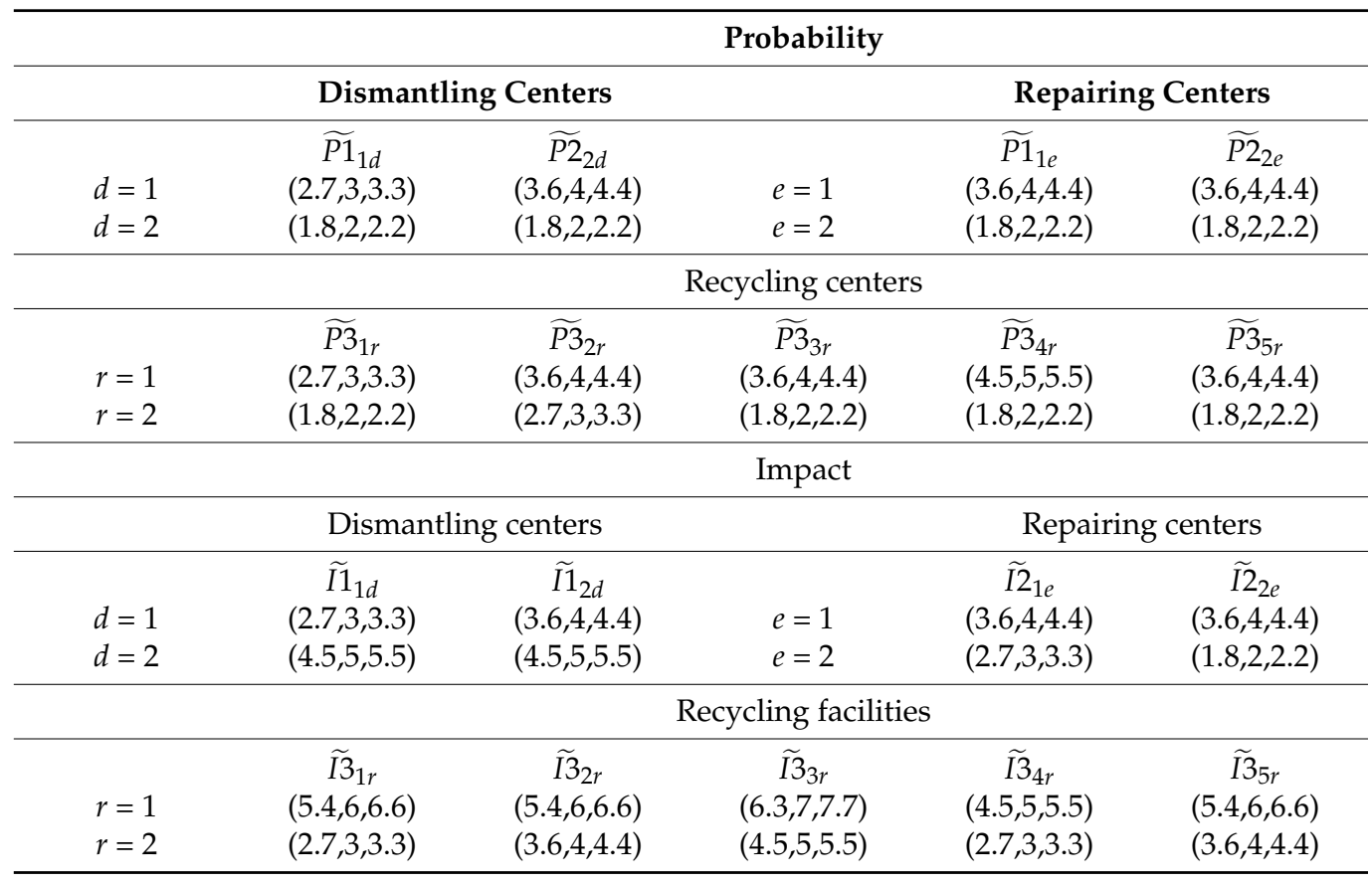

The possibility distributions of objective values are calculated for each discrete value $\alpha_{m}$ in the set $\mathrm{F}=\{0.4,0.5,0.6,0.7,0.8,0.9,1\}$ (as seen in column 1 of Table 16). After calculating all objective values with these $\alpha_{m}$ values by using CPLEX software, it is supposed that the decision-maker determines the value of $\underline{G}$ and $\bar{G}$ as $\$ 167,544$ USD (the minimum value in column 2 of Table 16) and \$219,605 USD (the maximum value in column 2 of Table 16), respectively. In other words, the DM is absolutely satisfied with the objective value which is lower than $\$ 167,544$ USD, while the DM does not accept the cost of more than $\$ 219,605$ USD. Based on Equations (36)-(39) and the t-norm minimum, the compatibility index of each solution and the degree of balance of each solution are easily obtained. These results are shown in columns 3-4 of Table 16.

According to the results in Table 16, a satisfactory solution of the fuzzy problem is found at $\alpha=0.7$, which is the highest degree balance. With $\alpha=0.7$, the result shows that the total cost of the RSC model is in the possibility distributions $(\$ 170,505 ; 187,369 ; 210,821)$. These figures can assist DM in terms of the overall cost when designing an RSC network. In the optimistic case, the total cost can be $\$ 170,505$ USD, whereas the figure can increase to $\$ 210,821$ USD in the pessimistic situation. The overall cost in the most likely case is $\$ 187,369$ USD. 
Table 15. Probability of accident occurrence and the impact of shipping between sites.

\begin{tabular}{|c|c|c|c|c|}
\hline \multirow[b]{2}{*}{$\begin{array}{c}\text { route c- } d \\
\qquad \begin{array}{c}d=1 \\
d=2\end{array}\end{array}$} & \multicolumn{2}{|c|}{ Probability } & \multicolumn{2}{|c|}{ Impact } \\
\hline & $\begin{array}{r}\widetilde{P 4}_{1 d} \\
\quad(2.7,3,3.3) \\
\quad(2.7,3,3.3)\end{array}$ & $\begin{array}{r}\widetilde{P 4}_{2 d} \\
\quad(1.8,2,2.2) \\
\quad(2.7,3,3.3)\end{array}$ & $\begin{array}{r}\widetilde{I 4}_{1 d} \\
\quad(1.8,2,2.2) \\
\quad(1.8,2,2.2)\end{array}$ & $\begin{array}{r}\widetilde{I 4}_{2 d} \\
\quad(2.7,3,3.3) \\
(2.7,3,3.3)\end{array}$ \\
\hline route $d-s$ & $\widetilde{P 5}_{1 s}$ & $\widetilde{P 5}_{2 s}$ & $\widetilde{I 5}_{1 \mathrm{~s}}$ & $\widetilde{I 5}_{2 s}$ \\
\hline$s=1$ & $(2.7,3,3.3)$ & $(2.7,3,3.3)$ & $(2.7,3,3.3)$ & $(2.7,3,3.3)$ \\
\hline$s=2$ & $(1.8,2,2.2)$ & $(2.7,3,3.3)$ & $(3.6,4,4.4)$ & $(3.6,4,4.4)$ \\
\hline route $d-e$ & $\widetilde{P 6}_{1 e}$ & $\widetilde{P 6}_{2 e}$ & $\widetilde{I \sigma}_{1 e}$ & $\widetilde{I \sigma}_{2 e}$ \\
\hline$e=1$ & $(3.6,4,4.4)$ & $(3.6,4,4.4)$ & $(3.6,4,4.4)$ & $(1.8,2,2.2)$ \\
\hline$e=2$ & $(2.7,3,3.3)$ & $(2.7,3,3.3)$ & $(2.7,3,3.3)$ & $(1.8,2,2.2)$ \\
\hline route $d-r$ & $\widetilde{P 7}_{1 r}$ & $\widetilde{P 7}_{2 r}$ & $\widetilde{I}_{1 r}$ & $\widetilde{I 7}_{2 r}$ \\
\hline$r=1$ & $(3.6,4,4.4)$ & $(3.6,4,4.4)$ & $(3.6,4,4.4)$ & $(3.6,4,4.4)$ \\
\hline$r=2$ & $(2.7,3,3.3)$ & $(2.7,3,3.3)$ & $(3.6,4,4.4)$ & $(2.7,3,3.3)$ \\
\hline $\begin{array}{l}\text { route } d-l \\
\quad l=1\end{array}$ & $\widetilde{P 8}_{1 l}(5.4,6,6.6)$ & $\begin{array}{l}\widetilde{P 8}_{2 l} \\
\quad(6.3,7,7.7)\end{array}$ & $\widetilde{I 8}_{1 l}(6.3,7,7.7)$ & $\widetilde{I}_{2 l}(5.4,6,6.6)$ \\
\hline route $e$-s & $\widetilde{P 9}_{1 s}$ & $\widetilde{P 9}_{2 s}$ & $\widetilde{I 9}_{1 s}$ & $\widetilde{I}_{2 s}$ \\
\hline$s=1$ & $(3.6,4,4.4)$ & $(2.7,3,3.3)$ & $(3.6,4,4.4)$ & $(2.7,3,3.3)$ \\
\hline$s=2$ & $(2.7,3,3.3)$ & $(1.8,2,2.2)$ & $(1.8,2,2.2)$ & $(1.8,2,2.2)$ \\
\hline route $r-m$ & $\widetilde{P 10}_{1 m}$ & $\widetilde{P 10}_{2 m}$ & $\widetilde{I 10}{ }_{1 m}$ & $\widetilde{I 10}_{2 m}$ \\
\hline$m=2$ & $(1.8,2,2.2)$ & $(1.8,2,2.2)$ & $(1.8,2,2.2)$ & $(1.8,2,2.2)$ \\
\hline $\begin{array}{l}\text { route } d-g \\
\quad l=1\end{array}$ & $\begin{array}{l}\widetilde{P 11_{1 l}} \\
\quad(4.5,5,5.5)\end{array}$ & $\begin{array}{r}\widetilde{P 11}_{2 l} \\
\quad(2.7,3,3.3)\end{array}$ & $\widetilde{I 11_{1 l}}(5.4,6,6.6)$ & $\widetilde{I 11}_{2 l}(3.6,4,4.4)$ \\
\hline
\end{tabular}

Table 16. $\alpha$-acceptable optimal solutions.

\begin{tabular}{cccc}
\hline $\begin{array}{c}\text { Feasibility } \\
\text { Degree }\end{array}$ & $\begin{array}{c}\text { Possibility Distributions } \\
\text { of Objective Value }\end{array}$ & $\begin{array}{c}\text { Compatibility Index } \\
\text { of Each Solution }\end{array}$ & $\begin{array}{c}\text { Degree of Balance of } \\
\text { Each Solution }\end{array}$ \\
\hline 0.4 & $(167,544 ; 182,128 ; 204,809)$ & 0.720 & 0.4 \\
0.5 & $(169,254 ; 183,972 ; 207888)$ & 0.684 & 0.5 \\
0.6 & $(169,864 ; 185,644 ; 208,663)$ & 0.652 & 0.6 \\
0.7 & $(170,505 ; 187,369 ; 210,821)$ & 0.619 & 0.619 \\
0.8 & $(173,029 ; 189,103 ; 211,795)$ & 0.586 & 0.586 \\
0.9 & $(175,816 ; 191,104 ; 214,036)$ & 0.547 & 0.547 \\
1 & $(176,262 ; 192,636 ; 219,605)$ & 0.518 & 0.518 \\
\hline
\end{tabular}

After solving the proposed model by an optimal software, the result also indicates that two dismantling centers $\left(\mathrm{d}_{1}, \mathrm{~d}_{2}\right)$, one repairing center $\left(\mathrm{e}_{1}\right)$, and two recycling centers $\left(r_{1}, r_{2}\right)$ should be constructed. Table 16 presents the flow of materials and components transported within the RSC network. For example, the second row in column 2 of Table 17 $\left(Q 1_{111}=34\right)$ indicates that there are 34 used products $(p=1)$ which are transferred from the collection center $(c=1)$ to the dismantling center $(d=1)$. Similarly, the last row of column 5 of Table $17\left(Q 4_{225}=170\right)$ shows that 170 units of recycling material $(I=5)$ are transported from the dismantling center $(d=2)$ to the recycling center $(r=2)$. The rest of the figures can be addressed in the same way. 
Table 17. The flow of materials and components within the network at $\alpha=0.7$ ( 3 rd scenario).

\begin{tabular}{|c|c|c|c|c|c|c|c|c|}
\hline No & $Q 1_{c d p}$ & $Q^{2} d s u$ & $Q 3_{d e w}$ & $Q^{4} d r i$ & $Q 5_{d l h}$ & $Q 6_{e s w}$ & $Q 7_{r m i}$ & $Q 8_{r l h}$ \\
\hline 111 & 34 & 392 & & 0 & 0 & & 219 & 55 \\
\hline 112 & 0 & 320 & & 98 & 0 & & 296 & 74 \\
\hline 121 & 282 & & 392 & 392 & & & & \\
\hline 122 & 276 & & 320 & 294 & & & & \\
\hline 211 & 364 & 277 & & 277 & 0 & & 309 & 77 \\
\hline 212 & 325 & 272 & & 277 & 0 & & 232 & 58 \\
\hline 221 & 0 & & 277 & & & 669 & & \\
\hline 222 & 0 & & 272 & & & 592 & & \\
\hline 113 & & & & 213 & 0 & & 386 & 97 \\
\hline 114 & & & & 316 & 0 & & 463 & 116 \\
\hline 115 & & & & 0 & 0 & & 80 & 20 \\
\hline 116 & & & & & 392 & & & \\
\hline 117 & & & & & 320 & & & \\
\hline 123 & & & & 179 & & & & \\
\hline \multicolumn{9}{|l|}{124} \\
\hline 125 & & & & 320 & & & & \\
\hline 213 & & & & 277 & 0 & & 141 & 35 \\
\hline 214 & & & & 272 & 0 & & & \\
\hline 215 & & & & 102 & 0 & & 386 & 97 \\
\hline 216 & & & & & 277 & & & \\
\hline 217 & & & & & 272 & & & \\
\hline 225 & & & & 170 & & & & \\
\hline
\end{tabular}

There are three scenarios to be considered in this study. The first scenario is that risk and uncertain factors are not considered in the proposed model while keeping the rest of the parameters as constant. The second scenario addresses the costs without incorporating uncertain parameters. The last scenario (the proposed model) is that risk costs and uncertain parameters are simultaneously incorporated in the model. The first scenario can be considered as the optimistic case where every factor works perfectly as expected and no risk occurs. The second case is less optimistic than the first case, but its consideration is still limited due to lack of uncertainty. The last scenario is the most comprehensive. Investigating all three cases will give us an overall insight of how strategy decisions, i.e., opening centers, will vary with different points of view. This insight is important since strategy decisions are not easy to change during an RSC operation planning horizon.

After solving these models with CPLEX software, the results show that the total cost of the first scenario is $\$ 171,906$ USD, while that of the second case is $\$ 192,508$ USD. The flow of materials and components of the 1st and 2nd scenarios are presented in Tables 18 and 19, respectively. The figure of the third scenario is the possibility distributions $(170,505 ; 187,369$; $210,821)$. As can be seen, the total cost of the second scenario is slightly higher than the most likely case in the third scenario (\$192,508 vs. \$ 187,369$)$. The likely explanation is that there is no interactive fuzzy solution approach considered to determine the optimal value to balance between the two conflicting issues: to enhance the objective value as well as to strengthen the degree of satisfaction of constraints. Furthermore, the total cost of the first scenario ( $\$ 171,906$ USD) is lower than the figure of the most likely case in the third scenario (\$187,369 USD), since risk costs are not incorporated in the model. Although the total costs of the first and second scenarios can be lower and higher than that of the proposed model (third scenario), the first and second scenarios cannot represent real situations in designing an RSC network for e-waste. 
Table 18. The flow of materials and components (1st scenario).

\begin{tabular}{|c|c|c|c|c|c|c|c|c|}
\hline No & $Q 1_{c d p}$ & $Q^{2} d s u$ & $Q 3_{\text {dew }}$ & $Q^{4} d r i$ & $Q 5_{d l h}$ & $Q 6_{e s w}$ & $Q 7_{r m i}$ & $Q 8_{\text {rlh }}$ \\
\hline 111 & 130 & 500 & 500 & 100 & 0 & 690 & 232 & 58 \\
\hline 112 & 0 & 330 & 330 & 410 & 0 & 610 & 480 & 120 \\
\hline 121 & 190 & 0 & 0 & 400 & & 0 & & \\
\hline 122 & 280 & 0 & 0 & 90 & & 0 & & \\
\hline 211 & 370 & 190 & 190 & 190 & 0 & 0 & 320 & 80 \\
\hline 212 & 330 & 280 & 280 & 190 & 0 & 0 & 72 & 18 \\
\hline 221 & 0 & 0 & 0 & & & 0 & 152 & \\
\hline 222 & 0 & 0 & 0 & & & 0 & & \\
\hline 113 & & & & 310 & 0 & & 400 & 100 \\
\hline 114 & & & & 320 & 0 & & 480 & 120 \\
\hline 115 & & & & 0 & 0 & & 224 & 56 \\
\hline 116 & & & & & 500 & & & \\
\hline 117 & & & & & 330 & & & \\
\hline 123 & & & & 190 & & & & \\
\hline 124 & & & & 10 & & & & \\
\hline 125 & & & & 330 & & & & \\
\hline 213 & & & & 280 & 0 & & 152 & 38 \\
\hline 214 & & & & 280 & 0 & & & \\
\hline 215 & & & & & & & 264 & 66 \\
\hline 216 & & & & & 190 & & & \\
\hline 217 & & & & & 280 & & & \\
\hline 225 & & & & & & & & \\
\hline
\end{tabular}

Table 19. The flow of materials and components (2nd scenario).

\begin{tabular}{|c|c|c|c|c|c|c|c|c|}
\hline No & $Q 1_{c d p}$ & $Q 2_{d s u}$ & $Q 3_{\text {dew }}$ & $Q 4_{d r i}$ & $Q 5_{d l h}$ & $Q 6_{e s w}$ & $Q 7_{r m i}$ & $Q 8_{r l h}$ \\
\hline 111 & 30 & 400 & & 0 & 0 & 0 & 232 & 58 \\
\hline 112 & 0 & 330 & & 100 & 0 & 0 & 312 & 78 \\
\hline 121 & 290 & 0 & 400 & 400 & & 0 & & \\
\hline 122 & 280 & 0 & 330 & 300 & & 0 & & \\
\hline 211 & 370 & 0 & 290 & 290 & 0 & 0 & 320 & 80 \\
\hline 212 & 330 & 0 & 280 & 290 & 0 & 690 & 240 & 60 \\
\hline 221 & 0 & 290 & 0 & & & 0 & & \\
\hline 222 & 0 & 280 & 0 & & & 610 & & \\
\hline 113 & & & & 210 & 0 & & 400 & 100 \\
\hline 114 & & & & 320 & 0 & & 480 & 120 \\
\hline 115 & & & & 0 & 0 & & 88 & \\
\hline 116 & & & & & 440 & & & \\
\hline 117 & & & & & 330 & & & \\
\hline 123 & & & & 190 & & & & \\
\hline \multicolumn{9}{|l|}{124} \\
\hline 125 & & & & 330 & & & & \\
\hline 213 & & & & 290 & 0 & & 152 & 38 \\
\hline 214 & & & & 290 & 0 & & & \\
\hline 215 & & & & 110 & 0 & & 400 & 100 \\
\hline 216 & & & & & 290 & & & \\
\hline 217 & & & & & 280 & & & \\
\hline 225 & & & & 170 & & & & \\
\hline
\end{tabular}

Note that if the DM is not satisfied with the solution, the DM can refine the goal values of $\underline{G}$ and $\bar{G}$. This change can still use the results obtained from the crisp $\alpha$-parametric model. Thus, it normally does not increase the complexity of the whole process.

\section{Conclusions and Further Work}

The result indicates a stable solution for opening centers, i.e., two dismantling centers $(\mathrm{d} 1, \mathrm{~d} 2)$, one repairing center (e2), and two recycling centers (r1, r2) at $\alpha=0.6,0.7$ and 0.8 , 
i.e., three cases which have the highest satisfaction degree. These decisions are classified as strategic decisions. In reality, strategy decisions are the most important decisions since they are very difficult to be changed. In contrast to strategy decisions are tactical planning decisions, i.e., the flow quantity between each pair of facilities. These decisions can be revised and corrected based on the realization of uncertain parameters. In this case, the values of strategy decisions are stable enough to apply. Furthermore, three scenarios with different configurations are also considered. Three scenarios also have three different configurations for opening repairing centers. The third and second scenarios require one repairing center each but at different locations, while the first scenario needs to open two repairing centers. The first scenario is an optimistic case, where there is no risk and the decision-maker overestimates the demands of the markets. The difference in strategy decisions between the second and the third scenarios can be explained as the results of not integrating the satisfaction of decision-makers into making the model.

Unlike forward supply chains, uncertainties and risks are challenging issues in RSC systems, which significantly affect the performance of RSC network design in real-world applications. To deal with the uncertainty of input data, an FMILP is proposed to find a satisfactory solution. The result of this research provides a practical solution. There are some vital contributions to the study. Firstly, the research simultaneously considered risk and uncertain factors for an e-waste RSC problem. Secondly, the fuzziness in most of the parameters including all related costs, capacity, risk, and the quantity of returned products was addressed in our model. Thirdly, three different scenarios were analyzed to provide useful insights for decision-makers to design an e-waste RSC network effectively. Lastly, the proposed method can provide a satisfactory solution, balancing two conflicting factors: the level of satisfaction of constraints and the objective value. In other words, if the level of satisfaction of constraints is high, the objective value would be worse.

Although FMLIP is a very effective tool to handle the uncertain parameters, the stability of the solutions is one of the most challenging issues in this approach. Unlike traditional linear programming, it is extremely difficult to conduct sensitivity analyses in FMILP due to the script transformation process. For future research, the simulationbased optimization approach should be considered to obtain a more stable solution. In this approach, the problem can be separated into two stages. In the first stage, strategy decisions relating to opening facilities are fixed and different realizations of uncertain parameters are created through simulation. With these realizations, tactical planning decisions, i.e., the flow quantity between each pair of facilities, can be optimized through solving the linear programming problem. This approach can help to obtain more robust solutions, especially for an important decision which cannot easily be corrected.

Author Contributions: In this study, L.T.T.D.: wrote original draft preparation; Y.A. and S.-H.L.: supervision and review the paper; P.N.K.P.: research model, T.T.T.: research data and edited the paper. All authors have read and agreed to the published version of the manuscript.

Funding: This research received no external funding.

Institutional Review Board Statement: Not applicable.

Informed Consent Statement: Not applicable.

Data Availability Statement: Not applicable.

Conflicts of Interest: The authors declare no conflict of interest.

\section{Nomenclature}

Decision variables:

$Q 1_{c d p} \quad$ the volume of used product $p$ sent from $c$ to $d$;

$\mathrm{Q} 2 d s u \quad$ the volume of reused component $u$ sent from $d$ to $s$;

$Q 3_{\text {dew }} \quad$ the volume of renewable component $w$ sent from $d$ to $e$;

$Q 4_{d r i}$ the volume of recycling material $i$ sent from $d$ to $r$; 
$Q 5$ dlh the volume of disposal substance $h$ sent from $d$ to $l$;

$Q 6_{\text {esw }}$ the volume of renewable component $w$ sent from $e$ to $s$;

$Q 7_{r m i}$ the volume of recycling material $i$ sent from $r$ to $m$;

$Q 8_{r l h} \quad$ the volume of disposal materials $h$ sent from $r$ to $l$;

$X_{d} \quad\{0,1\}$ variable, $X_{d}=1$ if a dismantling center is built at location $d, X_{d}=0$ otherwise;

$X_{e} \quad\{0,1\}$ variable, $X_{e}=1$ if a repairing center is built at location $e, X_{e}=0$ otherwise;

$X_{r} \quad\{0,1\}$ variable, $X_{r}=1$ if a recycling center is built at location $r, X_{r}=0$ otherwise.

\section{Appendix A}

In this study, a dataset is randomly generated in a reasonable manner and is based on published papers $[13,17,21,22,50,63,64]$. A summary of these data is presented in Table A1 as below:

Table A1. Referenced data based on published papers.

\begin{tabular}{|c|c|c|c|}
\hline Parameters & Quantity & $\begin{array}{c}\text { Units of } \\
\text { Measurement }\end{array}$ & References \\
\hline Used product & $2-5$ & units & {$[17,21]$} \\
\hline $\begin{array}{c}\text { Components (reuse parts, recycling } \\
\text { materials, etc.) }\end{array}$ & $1-10$ & units & {$[17,63]$} \\
\hline $\begin{array}{l}\text { Distance from site to site (i.e., } \\
\text { collection center to dismantling center) }\end{array}$ & $6-200$ & $\mathrm{~km}$ & {$[13,17,21]$} \\
\hline $\begin{array}{l}\text { Costs (transportation, recycling, } \\
\text { processing costs per unit) }\end{array}$ & $0.1-10$ & USD & {$[13,22,63]$} \\
\hline Fixed facility costs & 100-2000 & USD & {$[22,64]$} \\
\hline Risk & $1-10$ & & {$[50]$} \\
\hline
\end{tabular}

\section{References}

1. Richey, R.G.; Chen, H.; Genchev, S.E.; Daugherty, P.J. Developing effective reverse logistics programs. Ind. Mark. Manag. 2005, 34, 830-840. [CrossRef]

2. Ruan Barbosa de Aquino, Í.; Ferreira da Silva Junior, J.; Guarnieri, P.; Camara e Silva, L. The Proposition of a Mathematical Model for the Location of Electrical and Electronic Waste Collection Points. Sustainability 2021, 13, 224. [CrossRef]

3. Forti, V.; Baldé, C.P.; Kuehr, R.; Bel, G. The Global E-Waste Monitor 2020; United Nations University (UNU): Bonn, Germany; International Telecommunication Union (ITU): Geneva, Switzerland; International Solid Waste Association (ISWA): Rotterdam, The Netherlands, 2020.

4. Yang, J.; Lu, B.; Xu, C. WEEE flow and mitigating measures in China. Waste Manag. 2008, 28, 1589-1597. [CrossRef]

5. Aboelmaged, M. E-waste recycling behaviour: An integration of recycling habits into the theory of planned behaviour. J. Clean. Prod. 2021, 278, 4182. [CrossRef]

6. Sthiannopkao, S.; Wong, M.H. Handling e-waste in developed and developing countries: Initiatives, practices, and consequences. Sci. Total Environ. 2013, 463, 1147-1153. [CrossRef] [PubMed]

7. Namias, J. The Future of Electronic Waste Recycling in the United States: Obstacles and Domestic Solutions; Columbia University: New York, NY, USA, 2013.

8. Nagalingam, S.V.; Kuik, S.S.; Amer, Y. Performance measurement of product returns with recovery for sustainable manufacturing. Robot. Comput. Integr. Manuf. 2013, 29, 473-483. [CrossRef]

9. Rahman, S.; Subramanian, N. Factors for implementing end-of-life computer recycling operations in reverse supply chains. Int. J. Prod. Econ. 2012, 140, 239-248. [CrossRef]

10. Fleischmann, M.; Bloemhof-Ruwaard, J.M.; Dekker, R.; van der Laan, E.; van Nunen, J.A.E.E.; Van Wassenhove, L.N. Quantitative models for reverse logistics: A review. Eur. J. Oper. Res. 1997, 103, 1-17. [CrossRef]

11. Pishvaee, M.S.; Kianfar, K.; Karimi, B. Reverse logistics network design using simulated annealing. Int. J. Adv. Manuf. Technol. 2010, 47, 269-281. [CrossRef]

12. Lee, C.K.M.; Lam, J.S.L. Managing reverse logistics to enhance sustainability of industrial marketing. Ind. Mark. Manag. 2012, 41, 589-598. [CrossRef]

13. John, S.T.; Sridharan, R.; Ram Kumar, P.N.; Krishnamoorthy, M. Multi-period reverse logistics network design for used refrigerators. Appl. Math. Model. 2018, 54, 311-331. [CrossRef]

14. Amin, S.H.; Zhang, G.; Akhtar, P. Effects of uncertainty on a tire closed-loop supply chain network. Expert Syst. Appl. 2017, 73, 82-91. [CrossRef] 
15. Zarbakhshnia, N.; Soleimani, H.; Ghaderi, H. Sustainable third-party reverse logistics provider evaluation and selection using fuzzy SWARA and developed fuzzy COPRAS in the presence of risk criteria. Appl. Soft Comput. 2018, 65, 307-319. [CrossRef]

16. Rogers, D.S.; Melamed, B.; Lembke, R.S. Modeling and analysis of reverse logistics. J. Bus. Logist. 2012, 33, 107-117. [CrossRef]

17. Dat, L.Q.; Truc Linh, D.T.; Chou, S.Y.; Yu, V.F. Optimizing reverse logistic costs for recycling end-of-life electrical and electronic products. Expert Syst. Appl. 2012, 39, 6380-6387. [CrossRef]

18. Gomes, M.I.; Barbosa-Povoa, A.P.; Novais, A.Q. Modelling a recovery network for WEEE: A case study in Portugal. Waste Manag. 2011, 31, 1645-1660. [CrossRef] [PubMed]

19. Mahmoudi, H.; Fazlollahtabar, H. An integer linear programming for a comprehensive reverse supply chain. Cogent Eng. 2014, 1, 939440. [CrossRef]

20. Kilic, H.S.; Cebeci, U.; Ayhan, M.B. Reverse logistics system design for the waste of electrical and electronic equipment (WEEE) in Turkey. Resour. Conserv. Recycl. 2015, 95, 120-132. [CrossRef]

21. John, S.T.; Sridharan, R.; Kumar, P.R. Multi-period reverse logistics network design with emission cost. Int. J. Logist. Manag. 2017, 28, 127-149. [CrossRef]

22. John, S.T.; Sridharan, R. Modelling and analysis of network design for a reverse supply chain. J. Manuf. Technol. Manag. 2015, 26, 853-867. [CrossRef]

23. Phuc, P.N.K.; Yu, V.F.; Tsao, Y.C. Optimizing fuzzy reverse supply chain for end-of-life vehicles. Comput. Ind. Eng. 2016, 113, 757-765. [CrossRef]

24. Demirel, E.; Demirel, N.; Gökçen, H. A mixed integer linear programming model to optimize reverse logistics activities of end-of-life vehicles in Turkey. J. Clean. Prod. 2016, 112, 2101-2113. [CrossRef]

25. Galvez, D.; Rakotondranaivo, A.; Morel, L.; Camargo, M.; Fick, M. Reverse logistics network design for a biogas plant: An approach based on MILP optimization and Analytical Hierarchical Process (AHP). J. Manuf. Syst. 2015, 37, 616-623. [CrossRef]

26. Alshamsi, A.; Diabat, A. A reverse logistics network design. J. Manuf. Syst. 2015, 37, 589-598. [CrossRef]

27. Grunow, M.; Gobbi, C. Designing the reverse network for WEEE in Denmark. CIRP Ann. Manuf. Technol. 2009, 58, 391-394. [CrossRef]

28. Hazen, B.T.; Overstreet, R.E.; Hall, D.J.; Huscroft, J.R.; Hanna, J.B. Antecedents to and outcomes of reverse logistics metrics. Ind. Mark. Manag. 2015, 46, 160-170. [CrossRef]

29. Özceylan, E.; Paksoy, T. Fuzzy multi-objective linear programming approach for optimising a closed-loop supply chain network. Int. J. Prod. Res. 2013, 51, 2443-2461. [CrossRef]

30. Jindal, A.; Sangwan, K.S. Closed loop supply chain network design and optimisation using fuzzy mixed integer linear programming model. Int. J. Prod. Res. 2014, 52, 4156-4173. [CrossRef]

31. Pishvaee, M.S.; Razmi, J. Environmental supply chain network design using multi-objective fuzzy mathematical programming. Appl. Math. Model. 2012, 36, 3433-3446. [CrossRef]

32. Cheng, Y.H.; Lee, F. Outsourcing reverse logistics of high-tech manufacturing firms by using a systematic decision-making approach: TFT-LCD sector in Taiwan. Ind. Mark. Manag. 2010, 39, 1111-1119. [CrossRef]

33. Sadjadi, S.J.; Soltani, R.; Eskandarpour, A. Location based treatment activities for end of life products network design under uncertainty by a robust multi-objective memetic-based heuristic approach. Appl. Soft Comput. 2014, 23, 215-226. [CrossRef]

34. Ayvaz, B.; Bolat, B.; Aydın, N. Stochastic reverse logistics network design for waste of electrical and electronic equipment. Resour. Conserv. Recycl. 2015, 104, 391-404. [CrossRef]

35. Lee, D.H.; Dong, M. Dynamic network design for reverse logistics operations under uncertainty. Transp. Res. Part E Logist. Transp. Rev. 2009, 45, 61-71. [CrossRef]

36. Listeş, O.; Dekker, R. A stochastic approach to a case study for product recovery network design. Eur. J. Oper. Res. 2005, 160, 268-287. [CrossRef]

37. Kara, S.S.; Onut, S. A stochastic optimization approach for paper recycling reverse logistics network design under uncertainty. Int. J. Environ. Sci. Technol. 2010, 7, 717-730. [CrossRef]

38. Pishvaee, M.S.; Torabi, S.A. A possibilistic programming approach for closed-loop supply chain network design under uncertainty. Fuzzy Sets Syst. 2010, 161, 2668-2683. [CrossRef]

39. Dubois, D.; Fargier, H.; Fortemps, P. Fuzzy scheduling: Modelling flexible constraints vs. coping with incomplete knowledge. Eur. J. Oper. Res. 2003, 147, 231-252. [CrossRef]

40. Pishvaee, M.S.; Razmi, J.; Torabi, S.A. Robust possibilistic programming for socially responsible supply chain network design: A new approach. Fuzzy Sets Syst. 2012, 206, 1-20. [CrossRef]

41. Bilgen, B. Application of fuzzy mathematical programming approach to the production allocation and distribution supply chain network problem. Expert Syst. Appl. 2010, 37, 4488-4495. [CrossRef]

42. Liang, T.F. Distribution planning decisions using interactive fuzzy multi-objective linear programming. Fuzzy Sets Syst. 2006, 157, 1303-1316. [CrossRef]

43. Liang, T.F. Fuzzy multi-objective production/distribution planning decisions with multi-product and multi-time period in a supply chain. Comput. Ind. Eng. 2008, 55, 676-694. [CrossRef]

44. Liang, T.F.; Cheng, H.W. Application of fuzzy sets to manufacturing/distribution planning decisions with multi-product and multi-time period in supply chains. Expert Syst. Appl. 2009, 36, 3367-3377. [CrossRef] 
45. Ramezani, M.; Kimiagari, A.M.; Karimi, B.; Hejazi, T.H. Closed-loop supply chain network design under a fuzzy environment. Knowl. Based Syst. 2014, 59, 108-120. [CrossRef]

46. Doan, L.T.T.; Amer, Y.; Lee, S.H.; Phuc, P.N.K.; Dat, L.Q. E-Waste Reverse Supply Chain: A Review and Future Perspectives. Appl. Sci. 2019, 9, 5195. [CrossRef]

47. Hudnurkar, M.; Deshpande, S.; Rathod, U.; Jakhar, S. Supply Chain Risk Classification Schemes: A Literature Review. Oper. Supply Chain Manag. Int. J. 2017, 10, 182-199. [CrossRef]

48. Kumar, S.K.; Tiwari, M.; Babiceanu, R.F. Minimisation of supply chain cost with embedded risk using computational intelligence approaches. Int. J. Prod. Res. 2010, 48, 3717-3739. [CrossRef]

49. Zsidisin, G.A.; Ellram, L.M.; Carter, J.R.; Cavinato, J.L. An analysis of supply risk assessment techniques. Int. J. Phys. Distrib. Logist. Manag. 2004, 34, 397-413. [CrossRef]

50. El Dabee, F.; Marian, R.; Amer, Y. A novel optimization model for simultaneous cost-risk reduction in multi-suppliers just-in-time systems. J. Comput. Sci. 2013, 9, 1778-1792. [CrossRef]

51. Thun, J.H.; Hoenig, D. An empirical analysis of supply chain risk management in the German automotive industry. Int. J. Prod. Econ. 2011, 131, 242-249. [CrossRef]

52. Nooraie, S.V.; Mellat Parast, M. A multi-objective approach to supply chain risk management: Integrating visibility with supply and demand risk. Int. J. Prod. Econ. 2015, 161, 192-200. [CrossRef]

53. Li, G.; Fan, H.; Lee, P.K.C.; Cheng, T.C.E. Joint supply chain risk management: An agency and collaboration perspective. Int. J. Prod. Econ. 2015, 164, 83-94. [CrossRef]

54. Sheu, J.B. A coordinated reverse logistics system for regional management of multi-source hazardous wastes. Comput. Oper. Res. 2007, 34, 1442-1462. [CrossRef]

55. Sharma, A.; Revankar, A.M.; Sathvik, R.S. Risk management in reverse supply chain. In Proceedings of the International Conference on Challenges and Opportunities in Mechanical Engineering, Industrial Engineering and Management Studies, Bangalore, Indian, 11-13 July 2012.

56. Kazancoglu, Y.; Ozkan-Ozen, Y.D.; Mangla, S.K.; Ram, M. Risk assessment for sustainability in e-waste recycling in circular economy. Clean Technol. Environ. Policy 2020, 1-13. [CrossRef]

57. Parajuly, K.; Habib, K.; Liu, G. Waste electrical and electronic equipment (WEEE) in Denmark: Flows, quantities and management. Resour. Conserv. Recycl. 2017, 123, 85-92. [CrossRef]

58. Yuksel, H. An analytical hierarchy process decision model for e-waste collection center location selection. In Proceedings of the CIE 2009 International Conference on Computers \& Industrial Engineering, Troyes, France, 6-9 July 2009; pp. 1684-1689.

59. Sohani, N.; Chaurasia, M.K. Analysis of Risk Management for Reverse Supply Chain Network. Imp. J. Interdiscip. Res. 2016, 2. [CrossRef]

60. Jiménez, M.; Arenas, M.; Bilbao, A.; Rodriguez, M.V. Linear programming with fuzzy parameters: An interactive method resolution. Eur. J. Oper. Res. 2007, 177, 1599-1609. [CrossRef]

61. Heilpern, S. The expected value of a fuzzy number. Fuzzy Sets Syst. 1992, 47, 81-86. [CrossRef]

62. Parra, A.M.; Terol, B.A.; Gladish, P.B.; Uría, R.M.V. Solving a multiobjective possibilistic problem through compromise programming. Eur. J. Oper. Res. 2005, 164, 748-759. [CrossRef]

63. Doan, L.T.T.; Amer, Y.; Lee, S.H.; Phuc, P.N.K. Optimizing the Total Cost of an E-waste Reverse Supply Chain Considering Transportation Risk. Oper. Supply Chain Manag. Int. J. 2018, 11, 151-160. [CrossRef]

64. Soleimani, H.; Govindan, K. Reverse logistics network design and planning utilizing conditional value at risk. Eur. J. Oper. Res. 2014, 237, 487-497. [CrossRef] 